\title{
Weldability Of New Ferritic Stainless Steel For Exhaust Manifold Application
}

\author{
Vincent Villaret ${ }^{1-2, a-b}$, Frédéric Deschaux-Beaume ${ }^{1, c}$, Jean-Marie Fortain ${ }^{2, d}$, \\ Gilles Fras ${ }^{1, e}$, Fabien Januard ${ }^{2, f}$ \\ ${ }^{1}$ Laboratoire de Mécanique et Génie Civil - UMR 5508, Université Montpellier 2 \\ CC 048 Place Eugène Bataillon, 34095 Montpellier cedex 5, France. \\ ${ }^{2}$ AIR LIQUIDE / CTAS, 13 Rue d'épluches 95310 St OUEN L'AUMÔNE, France. \\ avincent.villaret@iut-nimes.fr, bvincent.villaret@airliquide.com, \\ ‘ffrederic.deschaux-beaume@iut-nimes.fr, djean-marie.fortain@airliquide.com, \\ egilles.fras@iut-nimes.fr, ${ }^{\mathrm{f}}$ fabien.januard@airliquide.com
}

Keywords: ferritic stainless steel, automotive exhaust, stabilization, columnar to equiaxed transition, welding.

\begin{abstract}
In the current context of fossil energy scarcity, car manufacturers have to optimize vehicles energy efficiency. This global and continuous improvement includes a change of the exhaust manifold design. Usually in cast iron, exhaust manifolds tend to be mechanically welded in order to fit new constraints such as lightness, durability, efficiency and small size. To achieve such requirements, ferritic stainless steels with high chromium content (19\%) and molybdenum (2\%) are developed. For the welding, the use of existing filler wire does not satisfy fully the application requirements. This leads to oxidation problems and / or thermal fatigue strength that drastically reduces assembly lifetime.

New flux cored wires are developed in the context of this study in order to provide molten zone characteristics close to those of the base metal. Different chemical compositions are tested in order to highlight the influence of stabilizing element on microstructure. Welding tests revealed the major influence of titanium on the grain refinement in the molten zone. A minimum Ti content of 0.45 weight $\%$ in the filler wire is required to be efficient as grain refiner.
\end{abstract}

\section{Introduction}

In an environment of industrial competition, ecological and economic arguments are crucial today, especially in the automotive sector. The manufacturers are adopting a global and continuous improvement approach, in particular to optimize the energy efficiency of their vehicles. Weight gain and increased motor efficiency, resulting in an increase in temperature of exhaust gas, are thus two major explored ways. The exhaust system is a set of complex parts, and the manifold is the part closest to the engine, so the hottest and most critical. Conventional cast iron design has evolved to manifolds with welded thinner steel sheets more appropriate for current constraints, lighter, with better resistance to service conditions (corrosion, thermal cycling, mechanical stress, and high temperature service). This evolution involves the development of new materials and assembly solutions adapted to these new technical and economic constraints. Among the various materials for such applications, ferritic stainless steels are certainly the most promising because they combine good corrosion resistance and advantageous properties at high temperature, for moderate cost compared to austenitic stainless steels.

In order to provide a solution to car manufacturers, ARCELOR MITTAL has developed a ferritic stainless steel, designated thereafter K44X. This material, produced in the form of thin sheets $(0.6$ to $2.5 \mathrm{~mm}$ ), has a special composition (Table 1) enables to guarantee specifications of the application, 
especially for the corrosion resistance and mechanical strength at high temperature. However, commercial welding filler materials which could correspond to the listed constraints do not exist.

Table $1-K 44 X$ chemical composition.

\begin{tabular}{|c|c|c|c|c|c|c|c|c|c|c|c|c|c|}
\hline \multirow{3}{*}{ K44X } & \multicolumn{13}{|c|}{ Composition [weight \%] } \\
\hline & $\mathrm{C}$ & $\mathrm{Si}$ & $\mathrm{Mn}$ & $\mathrm{P}$ & $S$ & $\mathrm{~N}$ & $\mathrm{Cr}$ & $\mathrm{Cu}$ & $\mathrm{V}$ & $\mathrm{Ni}$ & Mo & $\mathrm{Ti}$ & $\mathrm{Nb}$ \\
\hline & $<0.022$ & 0.6 & 0.3 & $<0.03$ & $<0.05$ & $<0.025$ & 19 & $<0.3$ & 0.1 & $<0.025$ & 1.9 & $<0.01$ & 0.6 \\
\hline
\end{tabular}

Ideally, the filler material and the welding process should allow obtaining welding with similar properties than the base material. However, the welding operation generally modifies the composition and the microstructure. For instance, nitrogen and carbon, that can be dissolved in liquid metal during welding, have very low solubility in the ferritic matrix, resulting in hardening and embrittling effects. Then, chromium carbides can be formed at grain boundaries, creating a deficiency of chromium in the matrix, and promoting intergranular corrosion. To prevent this phenomenon, low contents of niobium and/or titanium are generally added, to promote $\mathrm{Ti}$ or $\mathrm{Nb}$ carbide and nitride formation instead of chromium carbide [1]. If the niobium excess remaining in solid solution in ferritic matrix can improve the mechanical strength at high temperature, the titanium excess has generally a detrimental effect on the toughness, so its content must be adapted to the $\mathrm{C}$ and $\mathrm{N}$ content in the material [2]. To help to the determination of titanium and niobium contents required for a complete stabilization, some authors proposed "practical formula", more suited than stoechiometric formula [3-6]. The addition of $\mathrm{Ti}$ and $\mathrm{Nb}$ can also limit grain growth during the welding cycle, which is an important problem for ferritic stainless steels, by pinning effect thanks to the formation of precipitates at grain boundaries [6]. Finally, large columnar grains can be formed in the molten zone [1], having a detrimental effect on the mechanical properties of the assembly, especially on the fatigue behavior. With a titanium addition it is possible to obtain a molten zone with fine equiaxed-grains, due to the precipitation of titanium nitride particles in the liquid metal, acting as nucleation sites for equiaxed grains during solidification [7].

The goal of this study is to develop and test various metal cored wires (MCW), intended for ensuring mechanical properties, especially thermal fatigue and corrosion resistance, of assemblies of grade $\mathrm{K} 44 \mathrm{X}$ welded with processes currently used in the automotive industry. In this paper we show the first results concerning the effect of the composition of the filler wire and the welding cycle on the grain structure of the molten zone.

\section{Metal core wire development and welding tests}

The composition of the welded zone has to be as homogeneous as possible as the base metal, so the filler metal must contain similar contents of chromium, molybdenum and niobium to insure good corrosion resistance and high temperature strength, and to limit grains growth at high temperature. In addition, it has to contain titanium to promote equiaxed grains nucleation.

To adjust the composition, the choice of a metal cored filler wire is convenient because the additional elements can be introduced as powder mixture in the core. The external foil is an AISI 409 stainless steel, containing $12 \% \mathrm{Cr}$ and $0.2 \% \mathrm{Ti}$. $\mathrm{Cr}, \mathrm{Mo}, \mathrm{Nb}$ and $\mathrm{Ti}$ additional contents are then adjusted in the powder mixture of the core, to obtain the desired composition in the weld metal (Table 2). Here we must distinguish the compositions of the filler wire, of the deposited metal, and of the molten zones obtained after welding. The composition of deposited metal is so different from the filler wire, because some elements suffer losses by vaporization or reaction during the phenomenon of chemical transfer in the arc. Similarly, the weld metal has a different composition to the deposited metal, due to dilution with the base metal. Because of these phenomena, which depend on welding energy, the relationship between the filler wire composition and the desired molten zone composition is not direct. 
First analyses on deposited metals have revealed nitrogen contents between $0.012 \%$ and $0.023 \%$ and carbon contents between $0.021 \%$ and $0.037 \%$. The titanium and niobium contents required to stabilize the steel in the molten zone have been chosen from these values using practical stabilization formula, which are more common than stoechiometric formula [3-6]:

$$
\begin{aligned}
& \% \mathrm{Nb}=0.2+7(\% \mathrm{C}+\% \mathrm{~N}) \\
& \% \mathrm{Ti}=0.15+4(\% \mathrm{C}+\% \mathrm{~N}) \\
& 0.2+4(\% \mathrm{C}+\% \mathrm{~N})<\% \mathrm{Nb}+\% \mathrm{Ti}<0.8
\end{aligned}
$$

From these data, a calculation of stabilizing elements contents to be added in the filler wire was made taking into account the dilution of base metal in the molten zone, and the transfer rate of the elements in the arc. Finally, seven welding wires have been realized with different contents of titanium and niobium, in order to allow us to study the effect of these elements.

Table 2 - Desired composition of deposited metal.

\begin{tabular}{|c|c|c|c|c|c|c|c|c|c|c|c|c|}
\hline \multicolumn{10}{|c|}{ Composition (weight \%) } \\
\hline $\mathrm{C}$ & $\mathrm{Si}$ & $\mathrm{Mn}$ & $\mathrm{P}$ & $\mathrm{S}$ & $\mathrm{N}$ & $\mathrm{Cr}$ & $\mathrm{Cu}$ & $\mathrm{V}$ & $\mathrm{Ni}$ & $\mathrm{Mo}$ & $\mathrm{Ti}$ & $\mathrm{Nb}$ \\
\hline 0.01 & 0.6 & 0.3 & $<0.03$ & $<0.005$ & 0.01 & 19 & $<0.3$ & 0.1 & $<0.25$ & 1.9 & $\mathbf{0}$ to $\mathbf{0 . 6}$ & $\mathbf{0}$ to 0.8 \\
\hline
\end{tabular}

A Gas Metal Arc Welding (GMAW) process using a DIGIWAVE® generator has been used for all the welding tests. The welding gas is a mixture of Ar with $2 \% \mathrm{CO}_{2}$ (AIR LIQUIDE ARCAL 12), usually used for welding stainless steel in automotive industry. Two set of welding parameters have been determined for each filler wire, corresponding to different transfer modes, pulsed or shortcircuit. To have a good transfer, electrical parameters (voltage and intensity) have been adjusted for each filler wire, so the electric power is slightly different for each one. However, for each filler metal, the electric power and the welding speed always are higher in pulsed mode than in shortcircuit mode.

Table 3 - Welding parameters

\begin{tabular}{|c|c|c|c|}
\hline Transfer mode & Electric power $[\mathrm{W}]$ & Welding speed $\left[\mathrm{cm} \cdot \mathrm{min}^{-1}\right]$ & Linear welding energy $\left[\mathrm{J} . \mathrm{cm}^{-1}\right]$ \\
\hline Short-circuit & $1620-1840$ & 50 & $1945-2205$ \\
\hline Pulsed & $2540-2675$ & 70 & $2180-2290$ \\
\hline
\end{tabular}

\section{Results: morphology of welded joints and grains in the molten zone}

The results presented below are focused on microstructure observations and chemical analysis associated.

For all the compositions of filler wires, stable pulsed and short-circuiting transfers produce regular welded joint. The macrographs performed on the specimens allow us to calculate the dilution rate, which affect the composition of the molten zones. Dilution rates are lower in short-circuiting mode (between 19 and 37\%) than in pulsed mode (40 to 50\%), that could partly explain the lower content of titanium measured in the molten zone for each filler wire in pulsed mode.

The macrographs also highlight the geometric characteristics of the welds (Fig. 1). The beads obtained in pulsed welding show a better wetting than those obtained by short-circuiting. Based on the results of chemical analysis, we observe a detrimental effect of titanium content in the wetting of the molten zone for a given transfer mode, has show the comparison between Fig. 1A and 1C.

Micrographic observations show that depending on the thermal conditions (transfer mode) and on the filler wire composition, it is possible to obtain three types of molten zone structures (Fig. 1):

- Columnar grain structure with growth direction perpendicular to the welding direction (Fig $1 \mathrm{~A})$;

- Equiaxed fine-grained structure (Fig. 1 C); 
- Mixed structure comprising an equiaxed fine-grained and columnar grain zones (Fig 1 B).
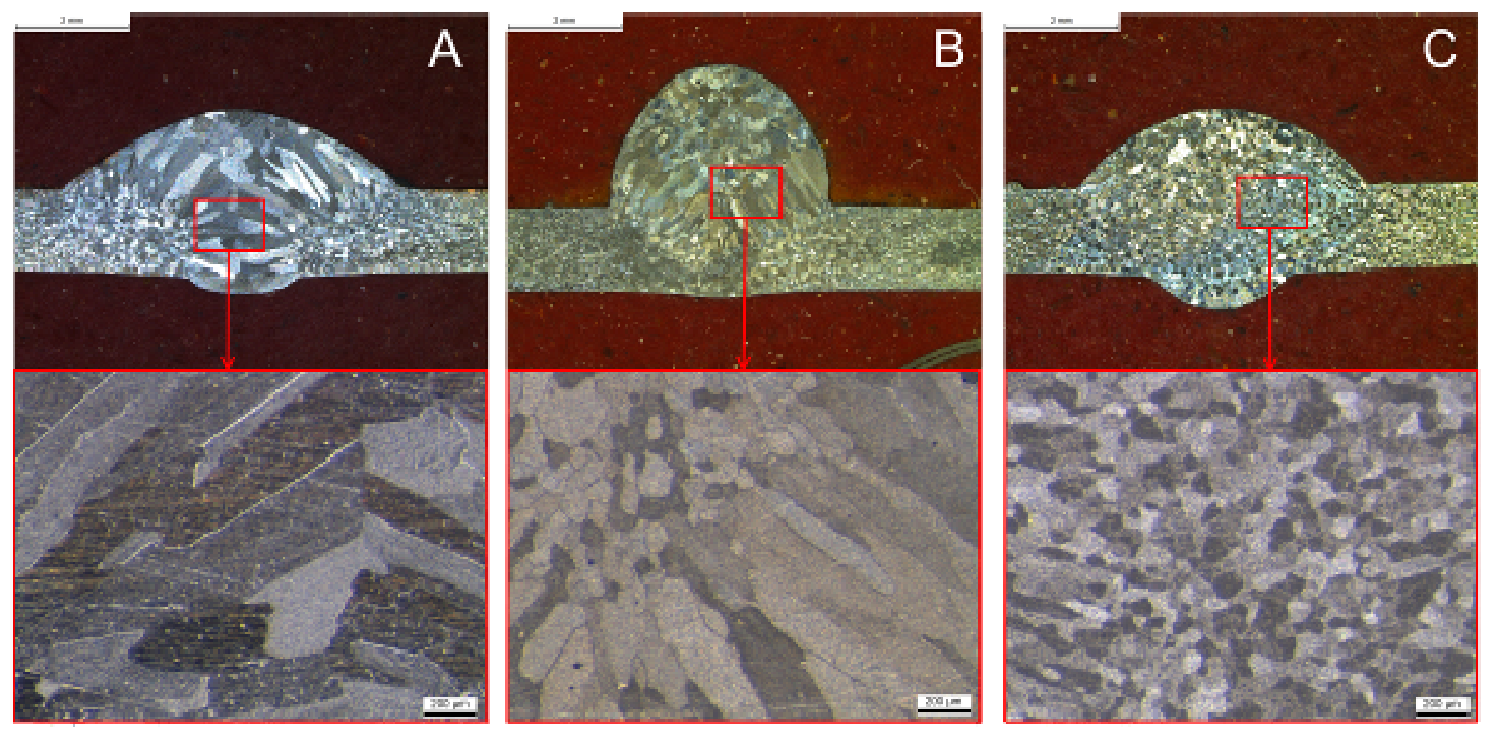

Figure 1: macrographs and micrographs of the molten zone: A-pulsed transfer, $0.10 \% \mathrm{Ti}, 0.021 \% \mathrm{~N}$, $0.036 \% \mathrm{C}$; B-short-circuiting transfer, $0.11 \% \mathrm{Ti}, 0.0205 \% \mathrm{~N}, 0.035 \% \mathrm{C}$; C-pulsed transfer, $0.15 \% \mathrm{Ti}$, $0.0231 \% \mathrm{~N}, 0.037 \% \mathrm{C}$.

According to all these results, it seems there is a minimum Ti content of about $0.12 \%$ required in the molten zone to produce grain refinement. Because of losses due to the transfer and to the dilution, which depend on energy parameters and transfer mode, the amount of Ti contained in the filler wire must be higher, typically about $0.45 \%$.

\section{Discussion}

Depending on the different parameters (chemical and thermal), the solidified zone can take two morphologies, columnar or equiaxed [7]. This microstructural change, commonly called Columnar to Equiaxed Transition or CET, has an important influence on the mechanical properties of the molten zone, a fine equiaxed grain structure conferring a better fatigue behaviour than a large columnar structure.

Basically, the occurrence of a CET requires two conditions [8]:

- Potential nuclei or embryos must exist ahead of the advancing columnar front (heterogeneous solidification);

- Favourable thermal conditions must allow embryos to grow and block columnar growth.

In stainless steels, titanium has a major effect on the CET, because titanium nitride particles act as nuclei for ferritic equiaxed grains nucleation, whereas we haven't seen any effect of the niobium, probably because niobium nitride or carbides are formed after the beginning of the ferrite solidification.

Considering only the thermal aspect, columnar growth is favoured by a high temperature gradient and a rather low growth rate of columnar grains, depending on welding speed. However, in welding, both growth rate and temperature gradient change along the solidification front at the rear of the weld pool (Figure $2 \mathrm{~A}$ ). A numerical modelling of the thermal phenomenon during welding allows us to evaluate these parameters along the border of the weld pool. Figure $2 \mathrm{~B}$ shows the evolution of both parameters from the edge of the weld pool to the centre. As well known, the temperature gradient is maximal on the edge and continuously decreases down to a minimal value in the centreline of the weld. At the opposite the growth rate is close to zero at the edges of the weld, and increases up to the welding speed in the centreline. Then, columnar growth is favoured in the edges, but if the solidification rate becomes too high relatively to the temperature gradient, a critical 
supercooling region appears before the columnar dendrite tip, and equiaxed grains can be formed, leading to a CET.

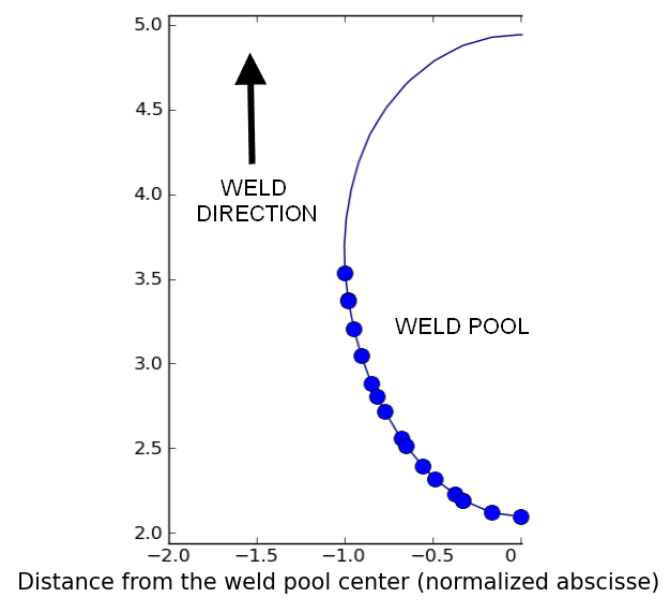

A

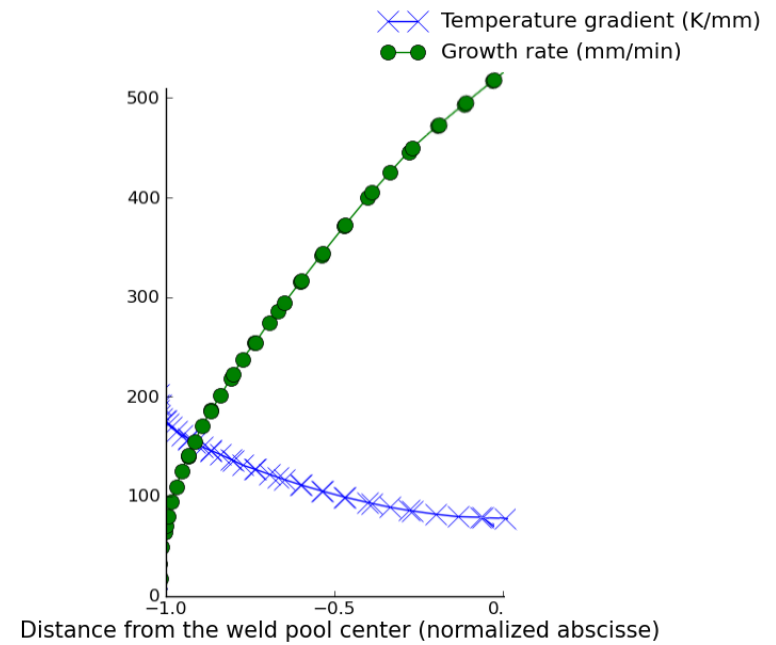

B

Figure 2: Temperature gradient and growth rate of columnar grains (B) along the rear border of the weld pool, shown in top view (A)

For heterogeneous nucleation of equiaxed grains, solid particles, here titanium nitride, must be present in the supercooling region. Supposing all these solid particles have the same size, we can consider that all equiaxed grains instantaneously nucleate for the same supercooling range $\Delta \operatorname{Tn}[10]$. Then the volumic fraction of equiaxed grains is controlled both by their growth rate, and by the advancing rate of the columnar front. Supposing the growth rate of equiaxed grains is proportional to $\Delta \mathrm{T}^{2}$, where $\Delta \mathrm{T}$ is the supercooling range, i.e. the difference between the liquidus temperature of the steel and the columnar dendrite tip temperature [10], then we can estimate the volumic fraction of equiaxed grains $f_{\text {eg }}$ by the Eq. 4 :

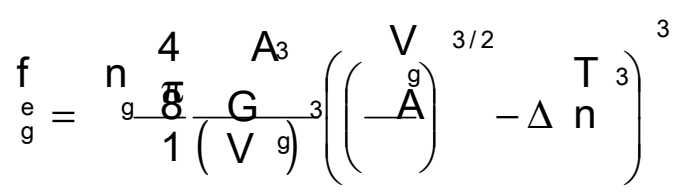

where $\mathrm{n}_{\mathrm{g}}$ is the grains density (corresponding to the density of TiN particles in the supercooling region), $\mathrm{G}$ the temperature gradient, $\mathrm{V}_{\mathrm{g}}$ the growth rate of columnar dendrites, and $\mathrm{A}$ is a constant.

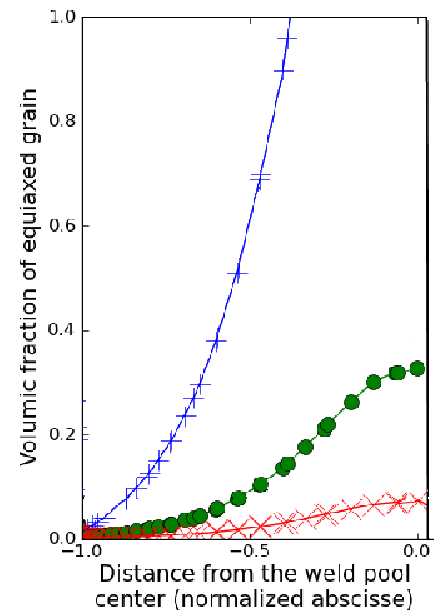

Figure 3: Evolution of volumic fraction of equiaxed grains for 3 grains densities

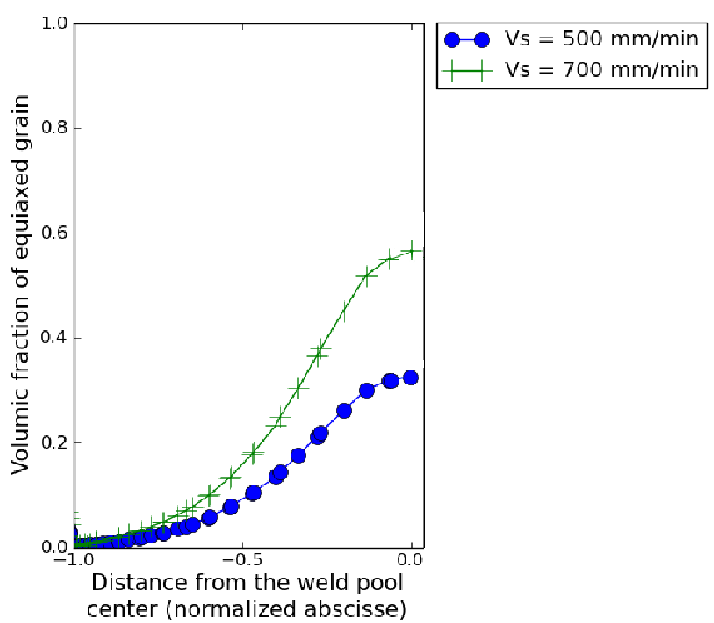

Figure 4: Evolution of volumic fraction of equiaxed grains for a grain density of $300 \mathrm{~mm}^{-3}$ 
corresponding to the micrographs $\mathrm{A}\left(\mathrm{n}_{\mathrm{g}}=65 \mathrm{~mm}^{-}\right.$

$\left.{ }^{3}\right), B\left(\mathrm{n}_{\mathrm{g}}=300 \mathrm{~mm}^{-3}\right)$ and $\mathrm{C}\left(\mathrm{n}_{\mathrm{g}}=2000 \mathrm{~mm}^{-3}\right)$

and for the two welding speeds

Fig. 3 shows the evolution of the equiaxed grains fraction $f_{\text {eg }}$ for the 3 grains densities deduced from the micrographs (Fig 1). The results obtained with this simple relation predict a completely equiaxed structure, except on the edges, for case C, a medium fraction of equiaxed grains (40\%) only on the centreline for case B, and a negligible fraction for case A, that is well correlated to the micrographs of figure 1. In Fig. 4, the effect of the welding speed on $\mathrm{f}_{\text {eg }}$ is presented according to Eq. (4), showing that for a similar density of TiN particles, an increase of welding speed promotes equiaxed structure. However, the real situation is more complex because a change in welding parameters simultaneously affects the temperature field around the weld pool and the content of transferred $\mathrm{Ti}$, and then the number of nucleation sites.

\section{Conclusion}

The aim of this study was to propose a welding solution for the K44X ferritic stainless steel by the development of homogeneous filler metal and the associated welding parameters. Several metal cored filler wires were tested, revealing the titanium content has a very important effect on the grain morphology of the molten zone. To allow the formation of a fine equiaxed grain structure, the $\mathrm{Ti}$ content in the molten zone must be higher than 0.12 weight $\%$, that require $\mathrm{Ti}$ content in the filler wire of about $0.45 \mathrm{wt} \%$ due to the dilution with the base metal and elements losses associate to the transfer. Thermal numerical modelling of a welding operation allows predicting qualitatively the microstructure type, columnar or equiaxed, and shows the number of nuclei in the supercooling region is very important. A slight increase of $\mathrm{Ti}$ (and $\mathrm{N}$ ) should be then increase the number of nuclei, and then produce a better grain refinement. However, structure obtained depends also on the welding energy parameters, that control the dilution, the elements losses during transfer, and the thermal cycles acting on the TiN precipitation and on the supercooling range.

\section{References:}

[1] J.L.MOIRON, Souder les aciers inoxydables / welding of stainless steel, Sirpe, 2000.

[2] FUJITA, N., New ferritic stainless steels in automotive exhaust system for clean environment, technical report $\mathrm{n}^{\circ} 81$ NIPPON STEEL, Janvier 2000.

[3] M. SEMCHYSHEN, A.P. BOND, H. J. D., Effects of Composition on Ductility and Toughness of Ferritic Stainless Steels, Toward Improved Ductility Toughness, Climax Molybdenum Development Co, 1972, 239-253.

[4] VAN ZWIETEN A. C. T. M., J. H. B., Some Considerations on the Toughness Properties of Ferritic Stainless Steels-A Brief Review, pressure vessel and piping, 1993, 56, 1-31.

[5] DUNDAS, H. J. \& BOND, A. P, Niobium and Titanium Requirements for Stabilization of Ferritic Stainless Steels, ASTM special technical publication, 1978, N656, 154-178.

[6] GORDON, W. \& VAN BENNEKOM, A.,Review of stabilization of ferritic stainless steels, Materials Science and Technology, 1996, 12, 126-131.

[7] J.C. VILLAFUERTE, H.W. KERr, S. D., Mechanisms of equiaxed grain formation in ferritic stainless steel gas tungsten arc welds, Materials Science and Engineering, 1995, A194, 187-191.

[8] W. KURZ, C. BEZENÇON, M. GÄUMANN, Columnar to equiaxed transition in solidification processing, Science and Technology of advanced materials 2, 2001, 185-191.

[9] DAVID, S.A., BABU, S.S., VITEK, J.M., Welding: Solidification and microstructure, JOM, 2003, June.

[10] J.A. DANTZIG, M. RAPPAZ, Solidification, EPFL Press, 2009 